\title{
Entrevista con Aristarco Aquino Solís: los derechos de las naciones originarias en Oaxaca
}

\author{
PARASTOO ANITA MESRI HASHEMI-DILMAGHANI
}

Introducción

Interview with Aristarco Aquino

Solís: The Rights of Indigenous

Nations in Oaxaca

PARASTOO ANITA MesRI

HASHEMI-DILMAGHANI

El Colegio de Tlaxcala,

Tlaxcala, México

parastooanita@yahoo.com.mx

Desacatos 59 ,

enero-abril 2019, pp. 168-171 ristarco Aquino Solís nació en 1951 en Yalálag, comunidad

zapoteca de la Sierra Norte de Oaxaca, y falleció en 2017. Fue maestro rural, ex líder sindical, y fungió como diputado local en su estado natal, de septiembre 1992 a septiembre 1995. Esta entrevista se llevó a cabo el 7 de julio de 2012, en la ciudad de Oaxaca de Juárez. En esa ocasión, pude preguntarle sobre el contexto en el que se hicieron las reformas a las leyes estatales en 1995 para plasmar los derechos colectivos de las naciones originarias. En particular, hablamos de los cambios al código electoral para reconocer la realidad de la entidad federativa más diversa en el país: la mayoría de los municipios no se rige por el sistema de partidos políticos para nombrar a sus autoridades, sino por el derecho electoral indígena.

El maestro Aquino Solís platicó sobre cómo se hicieron las reformas al código electoral oaxaqueño para reconocer de manera explícita la existencia de sistemas normativos indígenas, prácticas de las comunidades para nombrar a sus autoridades. Comentó que en octubre de 1992 asistió, como diputado local, a un encuentro en Tlahuitoltepec, distrito Mixe, organizado por el intelectual ayuuk o mixe Floriberto Díaz. Ahí se reunieron las comunidades mixes y una de sus "demandas insistentes" era que "ya no pase más el PRI [Partido Revolucionario Institucional] a recoger las planillas de nuestras autoridades y presentarlas como del partido porque nuestras autoridades no son electas por el sistema de partidos políticos".

El entonces gobernador Diódoro Carrasco llegó el último día de la reunión, cuando se leyeron los acuerdos y las demandas consensadas entre las comunidades. Se le dijo con mucha contundencia y claridad que ya no querían que los operadores regionales del PRI pasaran a "recoger 
estas ganadoras", es decir, la lista de los miembros de los ayuntamientos nombrados por las comunidades según sus normas y procedimientos propios. Se trataba de la exigencia de respeto y reconocimiento formal del derecho electoral indígena, del nombramiento de autoridades municipales en la asamblea general comunitaria. Esa demanda nació "de manera clara, formal, en Tlahui, en octubre de 1992”. En ese momento no se pensaba en una reforma a la ley electoral, pero la demanda era terminar con la simulación clientelista y "el uso, la manipulación de las elecciones indígenas".

Después, con el levantamiento zapatista del 1 de enero de 1994, los activistas y organizaciones indígenas de Oaxaca se sintieron "alentados". Aquino Solís asistió a las mesas de negociación y diálogo de San Andrés Larráinzar, en 1995 y 1996, como asesor del Ejército Zapatista de Liberación Nacional (EZLN), y participó en las mesas sobre "Cultura y derechos indígenas" y "Justicia y democracia". Don Aristarco, con Luis Villoro y Gustavo Esteva, negociaron con los representantes del gobierno federal en representación de la primera mesa.

El maestro Aquino Solís contó que en 1994 se empezó a luchar para la reglamentación del artículo 4o. de la Constitución federal, que hacía una mención vaga del carácter "multicultural” del país. El Instituto Nacional Indigenista (INI) estaba haciendo "simulacros de consulta", pero con el apoyo que él dio desde el congreso local, se convocó a foros a activistas y organizaciones indígenas, que tuvieron lugar en la Sierra Norte de Oaxaca, en San Cristóbal Lachirioag y Yalálag, distrito de Villa Alta; Atitlán, distrito Mixe, y Guelatao de Juárez, distrito de Ixtlán. En Guelatao, con la participación del maestro Jaime Martínez Luna, se formularon las propuestas sobre el reconocimiento del derecho electoral indígena, sus razones y fundamentos.

Don Aristarco describió su papel como diputado local, como el "recurso en la Cámara para impulsar la iniciativa”. Entre los esfuerzos realizados, visitó a académicos, como Salomón Nahmad Sittón y Gustavo Esteva, para conocer sus opiniones al respecto. El objetivo principal era que "los partidos totalmente sacaran las manos de las elecciones de autoridades internas".

Según recordó, se creó una corriente de opinión en varios sectores del estado de Oaxaca, con la fuerza suficiente para que "los principales afectados del resultado de la reforma, que eran los priistas, tuvieron que aceptarla". Además, relató que "hubo condiciones favorables, porque hubo capacidad de demanda de las organizaciones indígenas aquí, y el levantamiento zapatista también contribuyó. Hubo un ambiente favorable".

En la década de 1980, dijo don Aristarco, gente de fuera, en particular organizaciones no gubernamentales de derechos humanos, empezó a hablar de "catalogar" los procesos de nombramiento de autoridades en las comunidades indígenas como "usos y costumbres", para exigir que se respetaran, pero el término era ajeno al lenguaje comunitario de ese momento. Durante la entrevista, habló de "las formas tradicionales comunitarias de nombramiento de autoridades", en lugar de "usos y costumbres".

En relación con las razones por las cuales se exigió la referencia expresa en las leyes estatales a la

1 Con el propósito de posicionar en la arena política los derechos colectivos de los pueblos indígenas, y dado que se han construido connotaciones negativas en torno a la frase "usos y costumbres", que le niegan el carácter de un sistema normativo propio -como si el derecho indígena sólo fuera una fuente subsidiaria o secundaria del derecho mestizo o estatal-, he propuesto el concepto derecho electoral indígena durante el desempeño de cargos relacionados con el tema, en particular como funcionaria de la Sala Superior del Tribunal Electoral de Poder Judicial de la Federación (TEPJF) y del Tribunal Estatal Electoral del Poder Judicial de Oaxaca (TEEPJo), como asesora jurídica de la comunidad Purépecha de Cherani K'eri en el asunto del "cambio de régimen" y el acompañamiento a otras comunidades del país ante la TEPJF. 


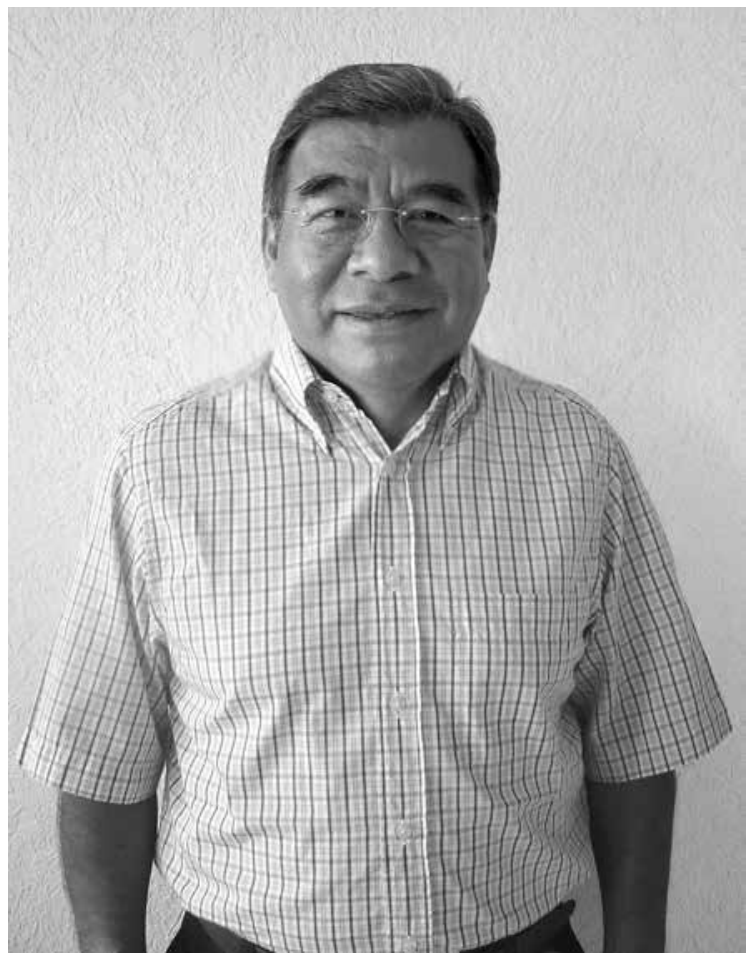

Cortesía de la familia Aquino En Oaxaca de Juárez, México, octubre de 2009.

existencia de normas y procedimientos electorales propios de las comunidades, Aquino Solís subrayó que antes de las reformas de 1995 no había nada en el derecho positivo - derecho escrito, derecho del Estado- para defender estos procesos y leyes comunitarios. Los funcionarios decían "esta ley no está vigente, esta ley no existe”, humillaban a la gente, y llegaban al extremo de reconocer otra autoridad como "legítima" cuando ellos ya la habían nombrado. En este sentido, insistió: “¿ahora quién duda de que se hagan elecciones por usos y costumbres? Son avances".

En este contexto social y político, el 30 de agosto de 1995 se aprobó el libro cuarto del Código de Instituciones Políticas y Procedimientos Electorales de Oaxaca, intitulado "De la renovación del ayuntamiento en los municipios de elección por usos y costumbres”. El libro incluía sólo cinco artículos, del 109 al 113, con referencias muy básicas y vagas sobre los municipios que cuentan con su propia normatividad electoral (Velásquez, 2000: 136-137). ${ }^{2}$

Desde entonces, el Código Electoral del estado de Oaxaca contempla dos posibilidades para las elecciones municipales, conocidas como el sistema de elecciones por partidos políticos y el de "usos y costumbres" (Recondo, 2007: 237), ahora llamados sistemas normativos indígenas. ${ }^{3}$ En 1995, de los 570 municipios de la entidad, en 412 se efectuaron las elecciones con el segundo (Flores, 2002: 182).

El 27 de septiembre de 1997, el Congreso estatal aprobó más cambios al Código Electoral. El libro cuarto, llamado "De la renovación de los ayuntamientos en los municipios que electoralmente se rigen por normas de derecho consuetudinario", fue ampliado de manera significativa. En las elecciones locales de 1998, 418 municipios nombraron a sus autoridades con la normatividad electoral indígena

El licenciado Cipriano Flores Cruz, entonces presidente del Consejo General del Instituto Estatal Electoral de Oaxaca (IEEO), afirmó: "Ios legisladores nos aventaron una papa caliente... estos artículos eran muy malos". Respecto al periodo entre 1995 y las reformas de 1997, comentó que "con muchos acuerdos", tomados en el Consejo General del IEEO, evitaron "aplicar lo que decía la ley" para no poner en peligro la gobernabilidad y estabilidad del estado (entrevista, Oaxaca de Juárez, 14 de noviembre de 2010).

Sobre la expresión "usos y costumbres" para referirse a normas y procedimientos electorales indígenas, Óscar Correas enfatizó: "esta expresión es verdaderamente lamentable. Porque ha conseguido hacerse usar por quienes se sabe bien que no tienen complejos raciales en contra de los indígenas. Sin embargo, sí es una expresión racista. Usada para referir [a] los sistemas normativos indígenas, tiene la virtud de desprestigiar la normatividad indígena, que no consigue ser vista como un sistema jurídico como cualquier otro. Y no lo consigue porque si los indígenas tienen usos y costumbres, entonces no tienen normas o éstas no constituyen un sistema" (2010: 232-233). 
o propia (Flores, 2002: 182-186). En la actualidad, 417 de los 570 municipios, es decir, casi 75\%, llevan a cabo sus elecciones municipales bajo el régimen del derecho electoral indígena. ${ }^{4}$

Al preguntarle a don Aristarco Aquino Solís cuál pensó que sería el resultado de las reformas de 1995, y si se contempló el fortalecimiento de las autonomías de las naciones originarias, contestó que "la autonomía era de la vida comunitaria". El objetivo era reconocer las formas propias de organización y toma de decisiones, por medio de la asamblea general comunitaria, la máxima autoridad en las comunidades indígenas y en la que se nombran a las autoridades comunitarias. Es decir, el enfoque era la vida comunitaria y se pensó en esos términos. D

4 La página web del hoy denominado Instituto Estatal Electoral y de Participación Ciudadana de Oaxaca (IEEPCO) tiene el "catálogo" de todos los municipios que se rigen por el derecho electoral indígena o "sistemas normativos internos" (véase <http://www.ieepco.org.mx/sistemas-normativos/catalogo-municipal>). Por encargo de Cipriano Flores Cruz, la antropóloga María Cristina Velásquez estudió en detalle el tema y el resultado se publicó en 2000, por el IEEO. Aquí no se reproducen las reformas ni los análisis de Flores - Velásquez, sólo se subrayan algunos puntos relevantes. El código fue reformado de nuevo en 2009 y 2012.

\section{Bibliografía}

Correas, Oscar, 2010, Teoría del derecho y antropología jurídica. Un diálogo inconcluso, Ediciones Coyoacán, México.

Flores Cruz, Cipriano, 2002 "Sistema electoral de los pueblos indígenas de Oaxaca”, en David Recondo y Aline Hémond (eds.), Dilemas de la democracia en México: Ios actores sociales ante la representación política, Instituto Federal Electoral/Centro de Estudios Mexicanos y Centroamericanos, México, pp. 175-194.

Recondo, David, 2007, La política del gatopardo. Multiculturalismo y democracia en Oaxaca, Centro de Investigaciones y Estudios Superiores en Antropología Social/Centro de Estudios Mexicanos y Centroamericanos, México.

Velásquez, María Cristina, 2000, El nombramiento. Las elecciones por usos y costumbres en Oaxaca, Instituto Estatal Electoral de Oaxaca, Oaxaca.

\section{Entrevistas}

Cipriano Flores Cruz, Oaxaca de Juárez, 14 de noviembre de 2010. 